\title{
A Decision Support System for Scour Management of Road and Railway Bridges Based on Bayesian Networks
}

\author{
ANDREA MARONI, ENRICO TUBALDI, DIMITRY VAL, \\ HAZEL MCDONALD, STEWART LOTHIAN, \\ OLIVER RICHES and DANIELE ZONTA
}

\begin{abstract}
Flood-induced scour is the excavation of material around bridge foundations due to the erosive action of flowing water and it is by far the leading cause of bridge failures worldwide. In the United States, scour is the cause of 22 bridges fail every year whereas in the UK, it contributed significantly to the 138 collapses of bridges in the last century. Monitoring an entire infrastructure network against scour is not economically feasible. A way to overcome this limitation is to install scour monitoring systems (SMSs) at critical bridge locations, and then extend information gained to the entire asset through a probabilistic approach. In this paper, we propose a Decision Support System (DSS) for road and railway bridge scour management that exploits information from a limited number of scour monitoring systems to achieve a more confined estimate of the scour risk for a bridge network. A Bayesian network $(\mathrm{BN})$ is used to describe conditional dependencies among the random variables involved. It allows estimating the present and future scour depth distribution using real-time information from monitoring of scour depth and river flow characteristics. Data collected by SMSs and BN's outcomes are then used to inform a decision model and thus support transport agencies' decision frameworks. The idea is to use this information to update the scour threshold after which bridges are closed. A case study consisting of several road bridges in Scotland is built to demonstrate the functioning of the DDS. They cross the same river and only one of them is instrumented with a SMS. The BN is found to estimate accurately the scour depth at unmonitored bridges and the decision model provides higher values of scour threshold compared to the ones implicitly chosen by transport agencies.
\end{abstract}

\section{INTRODUCTION \& BACKGROUND}

Flood-induced scour is the principal cause of bridge failures, resulting in significant loss of life, traffic disruption and economic losses [1]. Scour is the removal of sediment from around bridge abutment and piers. The total scour at bridge site results from the combination of different scour types: namely natural, constriction, and local scour [2].

Andrea Maroni, Enrico Tubaldi, and Daniele Zonta, University of Strathclyde, 75 Montrose St, Glasgow, G1 1XJ

Dimitry Val, Heriot-Watt University, Edinburgh Campus, Boundary Rd N, Edinburgh, EH14 4AS Hazel MacDonald, Transport Scotland, 58 Port Dundas Rd, Glasgow, G4 OHF

Stewart Lothian, Network Rail Scotland Route, 151 St Vincent St, Glasgow, G2 5NW

Oliver Riches, ARUP Scotland, Scotstoun House, South Queensferry, EH30 9SE 


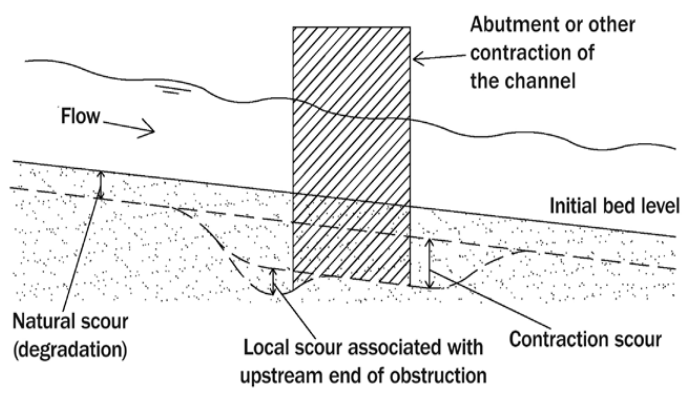

Figure 1. Schematic illustrating total scour [2].

While the first type is associated with the natural evolution of the river bed, the two other types are associated with the presence of a bridge (Figure 1). Constriction scour is the result of confining the width of the river channel, for instance between bridge abutments and piers, while local scour is caused by the interference of individual structural elements with the flow. Scour processes occur naturally and are expected to occur at most bridges [2], since every structure founded on river bed is prone to scour around its foundations. When the scour depth becomes significant, the foundation capacity may be compromised, leading to structural instability and catastrophic failure.

In the UK, there are more than 9,000 bridges over waterways. According to [3], abutment and pier scour is identified as the most common cause of 138 bridge failures during the period 1846-2013. Almost 95,000 bridge spans are susceptible to scour processes. Reviews of 1,502 river crossing failures that occurred in the USA in the period 1966-2005 revealed scour is the cause of 58\% of the recorded failures [4].

Network Rail (NR) owns 19,000 bridges nationally: 8,700 of these structures are held within a National Scour Database. For the Scotland Route, 1,750 structures are routinely inspected for scour, and 58 are considered to be at high risk. Transport Scotland (TS) is responsible for the Scottish trunk road network including 1,567 bridges or culverts over water. Of these, around $8 \%$ are currently classified as needing detailed consideration, including possible scour monitoring and protection measures.

The scour risk assessment is an important component of any bridge management system. This assessment should combine information on the scour hazard, the bridge vulnerability, and the consequences of failure. It should involve a probabilistic approach due to the many uncertainties inherent to the future flood occurrence and intensity, the bridge state, and capability to withstand the effects of the scour action [5].

Structural health monitoring (SHM) should help in making proper decisions about structural management, such as the assessment of a structural state. SHM and decisionmaking, are two separate processes, occurring one downstream of the other; monitoring is about acquiring information, not about making decisions. Conversely, decisionmaking is about identifying and choosing the optimal action to undertake based on the structural state assessed in the previous step [6].

The current practice for bridge scour inspection depends on visual checks carried out at regular intervals. TS and NR assess the scour risk using the Procedures BD 97/12 [7] and EX2502 [8], respectively. The decision frameworks followed by TS and NR are defined by their own plan, the "Scour Management Strategy and Flood Emergency Plan" [9] and the "Scotland Adverse and Extreme Weather Plan" [10]. They provide a framework for the management of bridges after an extreme weather event.

In this paper, the prototype of a DSS for bridge scour management is presented; it consists of a scour hazard model and a decision model. The former model is based on a 
$\mathrm{BN}$ able to estimate the depth of scour in the surrounding of bridge foundations. In particular, the $\mathrm{BN}$ can estimate the present and future scour depth using information from the monitored scour depth and river flow characteristics. The latter model can update the scour threshold after which the bridge is closed by exploiting BN's outcomes and observations collected by a scour monitoring system (SMS). Section 2 illustrates the BN for scour depth prediction and the decision model. Section 3 presents the bridge network built to demonstrate the functioning of the BN. Three bridges located over the same river are considered, with only one instrumented with a SMS. Section 4 reports some results obtained by applying the proposed framework.

\section{METHODOLOGY}

Monitoring any location of a bridge stock is not economically feasible. One way to overcome this issue is to install scour monitoring systems only at critical locations and then using a probabilistic approach to extend this information to the entire asset. A Bayesian Network (BN) can be used for this purpose. A BN is a probabilistic graphical model that represents a set of random variables and their conditional dependencies via a directed acyclic graph comprised of nodes and links [11].

The presence of a link between two nodes means that the node appearing earlier in the chain has a direct influence upon the other connected node. In BN terminology, a node is a parent of a child if there is a link from the former to the latter, whereas any node without parents is called a root node. Probabilistic inference in BNs takes two forms: predictive analysis that is based on evidence on root nodes and Bayesian learning where observations enter into the $\mathrm{BN}$ through child nodes [12]. The child node probability distribution functions (pdfs) can be estimated and updated by carrying out the former analysis, whereas the latter one allows updating root node pdfs when new information enters into the BN through a child node.

In recent years, there has been an increasing amount of literature on the use of BNs proving that this framework is a growingly popular approach to represent probabilistic models. BNs have become quickly popular in every field of studies thanks to their excellent performance and suitability on dealing with a wide range of problems involving uncertainty and probabilistic reasoning. BNs started to be used for Bayesian modelling in engineering risk analysis due to their ability to manage many dependent random variables [13]. Past applications to bridge assets addressed particularly seismic risk [14]. Bayesian network relies on a single tool, the Bayes' theorem shown in Eq. (1):

$$
\operatorname{pdf}(\theta \mid \mathbf{y})=\frac{\operatorname{pdf}(\theta) \times \operatorname{pdf}(\mathbf{y} \mid \theta)}{\operatorname{pdf}(\mathbf{y})}
$$

where $p d f(y \mid \theta)$ is the likelihood of the observed data $\boldsymbol{y}$ given the parameter $\theta, p d f(\theta)$ is the prior pdf of parameter $\theta, p d f(\theta \mid \boldsymbol{y})$ is the posterior probability of $\theta$, and $p d f(\boldsymbol{y})$ is called evidence. Bayes' rule describes how the probability of parameter $\theta$ changes given information gained from measured data $y$.

\section{Bayesian Network for scour depth estimation}

The BN employed in the scour hazard model is developed according to the BD 97/12 [7]. Starting from the river flow characteristics (such as river flow $Q$ and upstream 


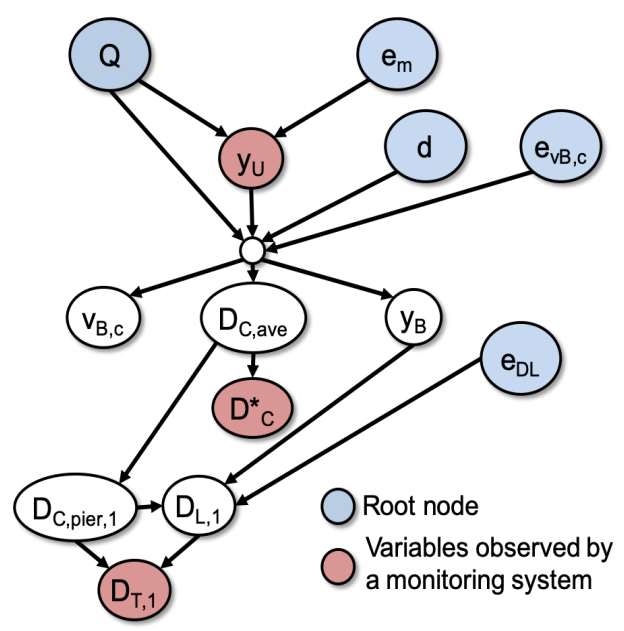

Figure 2. BN for scour estimation.

river level $y_{U}$ ), the total scour depth $D_{T}$ is estimated by summing the effects of constriction scour $\left(D_{C}\right)$ and local scour $\left(D_{L}\right)$ (Figure 2). Model uncertainties are added to reproduce the randomness of the estimation processes.

Manning equation is used to describe the relationship between $Q$ and $y_{U}$. Two model uncertainties are employed: $e_{M}$ is the correlated model error of the Manning equation and ${ }^{(j)} e_{M}$ is the uncorrelated model error in the $\mathrm{j}^{\text {th }}$ bridge. $Q, y_{U}$ and the bed material grain size $d$ are then the input of a nonlinear system consisting of 3 equations - the ColebrookWhite equation [2], the conservation of fluid mass, and the Bernoulli equation - uses to evaluate the average constriction scour $D_{c, \text { ave }}$, the water level through the bridge $y_{B}$, and the threshold velocity $v_{B, c}$. The last two equation are considered deterministic, therefore, model errors are added to the Colebrook-White equation alone: the correlated, $e_{v B, c}$ and the uncorrelated error, ${ }^{(j)} e_{v B, c}$. The mechanism causing local scour at piers is the formation of vortices at their base, and the pier width $W_{P}$ is the primary controlling parameter. Two model uncertainties are again added: $e_{D L}$ and the uncorrelatated ${ }^{(j)} e_{D L}$.

With reference to the presented $\mathrm{BN}$, three quantities are monitored: $y_{U}, D_{T}$ and the constriction scour $D^{*}$ measured in the middle of the channel. Environmental agencies can provide water level data from gauging stations while SHM sensors to detect scour exist in the market [15]. When new observations become available, the BN model allows propagating information through the network to update probabilities [11]. For this reason, BN can be merged with SHM systems to update the risk map of infrastructure systems. The BN solution can be broken down into three steps: (i) defining the prior pdfs of the root nodes; (ii) splitting the BN into three sub-networks to have three different updating: $y_{U}$ updates $e_{M} ; D^{*}{ }_{C}$ and $y_{U}$ update $e_{v B, c}$ and $d ; D_{T}, y_{U}$ and $D^{*}{ }_{C}$ update $e_{D L}$; and (iii) updating the descendant nodes.

The $\mathrm{BN}$ can be extended to a second bridge with $\mathrm{N}$ piers because the scour estimation is based on the same models; therefore, the correlated model uncertainties are, in turn, the same ones. These connections allow the BN to spread information gained from a SMS to each sub-network (i.e., unmonitored bridge).

\section{Decision model}

The actions to be taken by TS and NR in the aftermath of a flooding event are defined by two plans $[9,10]$. They provide the triggers that determine what actions needs to take place and a "visual" decision scheme based on water level markers. TS 
defines a red marker in correspondence of the 1 in 200-year flood level whereas NR as the water level associated with a Priority Score $\geq 16$. The transport agencies fix these thresholds by choosing a level of risk they are willing to accept, such that the losses due to the bridge closure equal those due to bridge failure.

Both transport agencies use the relative scour depth $D_{R}$ (i.e., ratio between $D_{T}$ and the foundation depth $D_{F}$ ) to categorise bridges at high risk of scour. TS classification consists of five classes while NR method has six classes, and bridges with the highest priority fall into class 1 in the two procedures. When a bridge is categorised into category 1 or 2 , it is considered at high scour risk for both agencies.

The idea behind the proposed decision model is to use the updated scour depth to inform decision about bridge scour management. In particular, the relative scour depth $D_{R}$ is used as quantity to trigger actions.

The scour failure probability $P_{F}$ of a bridge is the probability that the normalised scour demand is greater than the normalised scour capacity of the bridge. The prior normalised scour demand $D_{P r}$ (Figure 4) can be expressed as a Normal distribution:

$$
D_{\operatorname{Pr}} \sim \mathcal{N}\left(\bar{D}_{0}, \sigma_{D_{0}}\right)
$$

where $\bar{D}_{0}$ is the prior threshold of $D_{R}$ corresponding to a high risk of scour according to transport agencies, and $\sigma_{D 0}$ is the prior standard deviation of $D_{R}$ obtained with the BN.

A fragility function $F_{C}$, consistent with the risk class given by BD97/12 (Figure 4), relates $D_{R}$ to the probability of failure $P_{F}$, and the unconditional prior probability of failure $P_{F, D 0}$ can be written as:

$$
P_{F, D_{0}}=\int_{D_{R}} \mathcal{N}\left(\bar{D}_{0}, \sigma_{D_{0}}, D_{R}\right) F_{C}(D) \mathrm{d} D_{R}
$$

Eq. (2) expresses the failure probability implicitly chosen by transport agencies when they fix their thresholds (i.e., the mean value of the prior scour demand $D_{P r}$ is the agency's threshold).

The BN provides an updating of the total scour depth distribution (i.e., posterior pdf in Figure 4). This BN's outcome can be used to express the posterior scour demand $D_{P}$ :

$$
D_{P} \sim \mathcal{N}\left(\bar{D}, \sigma_{P}\right)
$$

where $\bar{D}$ is the posterior scour threshold and $\sigma_{P}$ is the posterior standard deviation updated by the BN. The probability of failure must remain equal to the one "a priori" (Eq. (3)), to be consistent with the threshold defined by transport agencies. Thus:

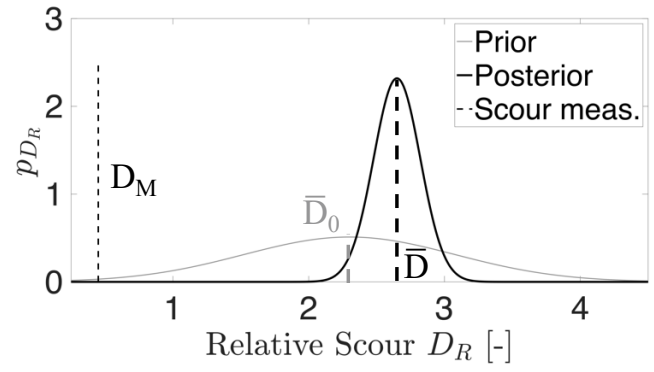

Figure 4. Scour demand pdfs.

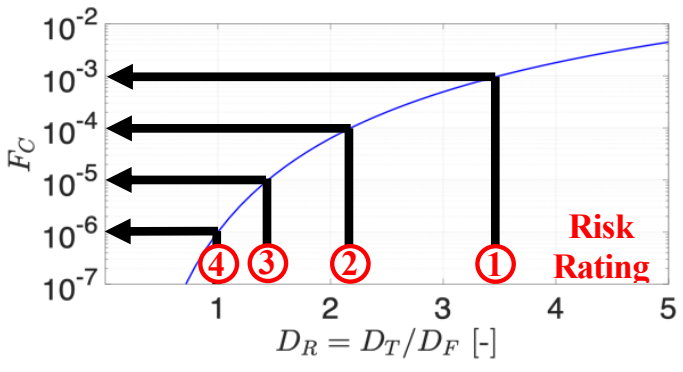

Figure 4. Fragility function for scour capacity FC. 


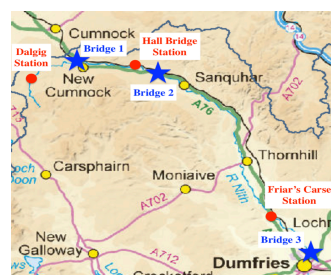

(a)

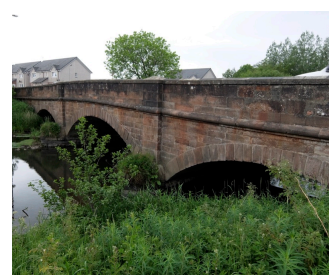

(b)

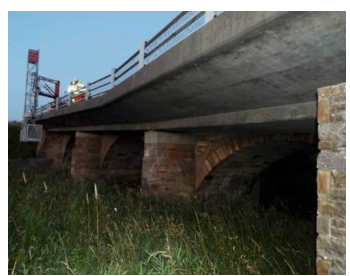

(c)

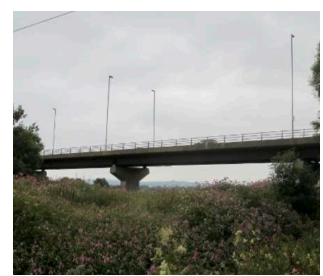

(d)

Figure 5. (a) Map; (b) A76 200 bridge; (c) A76 120 Guildhall bridge; and (d) A75 300 Dalscone bridge

$$
P_{F, D}=\int_{D_{R}} \mathcal{N}\left(\bar{D}, \sigma_{P}, D_{R}\right) F_{C}(D) \mathrm{d} D_{R}=P_{F, D_{0}}
$$

where $P_{F, D 0}$ is expressed in Eq. (3). The updated demand threshold corresponding to a high risk of scour is the value of $\bar{D}$ that satisfies Eq. (5).

\section{CASE STUDIES}

The functioning of the developed DSS is demonstrated using a small bridge network, consisting of bridges managed by TS in south-west Scotland (Figure 5). The bridges cross the same river (River Nith), and only the first bridge is instrumented with a PSMS. The aim is to exploit observations on Bridge 1 in order to predict scour depth at other bridge locations. Three bridges with significant scour events in the past are chosen from the TS scour database:

- Bridge 1: A76 200 Bridge on River Nith in New Cumnock. It is a 3-span stonemasonry arch bridge, with two piers in the riverbed founded on spread footings.

- Bridge 2: A76 120 Guildhall bridge in Kirkconnel. It is a 3-span masonry arch bridge, with one pier in the riverbed founded on spread footings.

- Bridge 3: A75 300 Dalscone bridge in Dumfries. It is a 7-span steel-concrete composite bridge, with one pier in the riverbed founded on pile foundations.

The final BN for the estimation of the total scour at every bridge pier is depicted in Figure 6. Each subnetwork related to each bridge is identifiable; correlated errors and the bed material grain size are root nodes in common with each bridge. $Q$ is not a common root node because water flow data are available for every bridge.



Figure 6. BN developed for the case study. 


\section{RESULTS}

Normal pdfs are employed for every variable except for river flows; a log-normal pdf is adopted because the discharge cannot be negative. The prior pdfs of the model uncertainties are set as Normal distributions with zero mean and a coefficient of variation. The parameters of the log-normal pdfs are based on the SEPA's gauging station data of the last ten years.

The predictive analysis has been carried out by running a Monte Carlo method. 10.000 samples were extracted from every pdf to estimate a prior pdf of the total scour depth at each pier. The outcomes are displayed in red in the second column of Figure 7. The accuracy of the estimation at unmonitored piers is not satisfactory (i.e., $\sigma \approx 75 \mathrm{~cm}$ ). The Transitional Markov Chain Monte Carlo (TMCMC) algorithm [16] is used to perform the Bayesian learning analysis and update the root nodes. 1,000 samples are extracted at each stage of the TMCMC method, and the execution is repeated 100 times for each updating to eliminate the influence of randomness. The peak value of upstream river levels $y_{U}$ is chosen to simulate a heavy river flood condition and scour data are assumed to represent a critical situation: $20 \mathrm{~cm}$ for constriction scour depth $\mathrm{D}^{*} \mathrm{C}$ and 45 cm for total scour depth $\mathrm{D}_{\mathrm{T}}$ at pier 1 of A76 200 bridge.

The algorithm estimated value of total scour on the pier 2 that is equal to the one measured at pier 1 . It is the most probable result since the piers belong to the same bridge, their geometry is the same, and the river bed material is the same. However, it is an uncertain variable, with a standard deviation of $17 \mathrm{~cm}$. It is noteworthy that the standard deviation has reduced from $76 \mathrm{~cm}$ to $17 \mathrm{~cm}$, which is a decrease of around $80 \%$, due to the added information. The total scour $D_{T}$ at the unmonitored bridges can also be evaluated. A value of standard deviation close to $21 \mathrm{~cm}$ is obtained. This constitutes an increase (more than 70\%) in the accuracy compared to the prior results.

The third column of Figure 7 shows the outcomes of the scour threshold updating by exploiting the results obtained from the BN. The graphs depict the plotting of Eq. (5) by varying the value of threshold $\bar{D}$. The probability of failure $P_{F, D O}$ (red line) is a constant value because the threshold is chosen "a priori". The intersection of the two straight lines provides the updated threshold that satisfies Eq. (5). According to the scour risk classification performed by TS, the prior threshold $\bar{D}_{0}$ is chosen equal to 2.3 , the one that defines the boundary between class 3 and class 2, by assuming a priority factor equal to 2. Figure 7 shows an update of the scour threshold for all the three bridges.
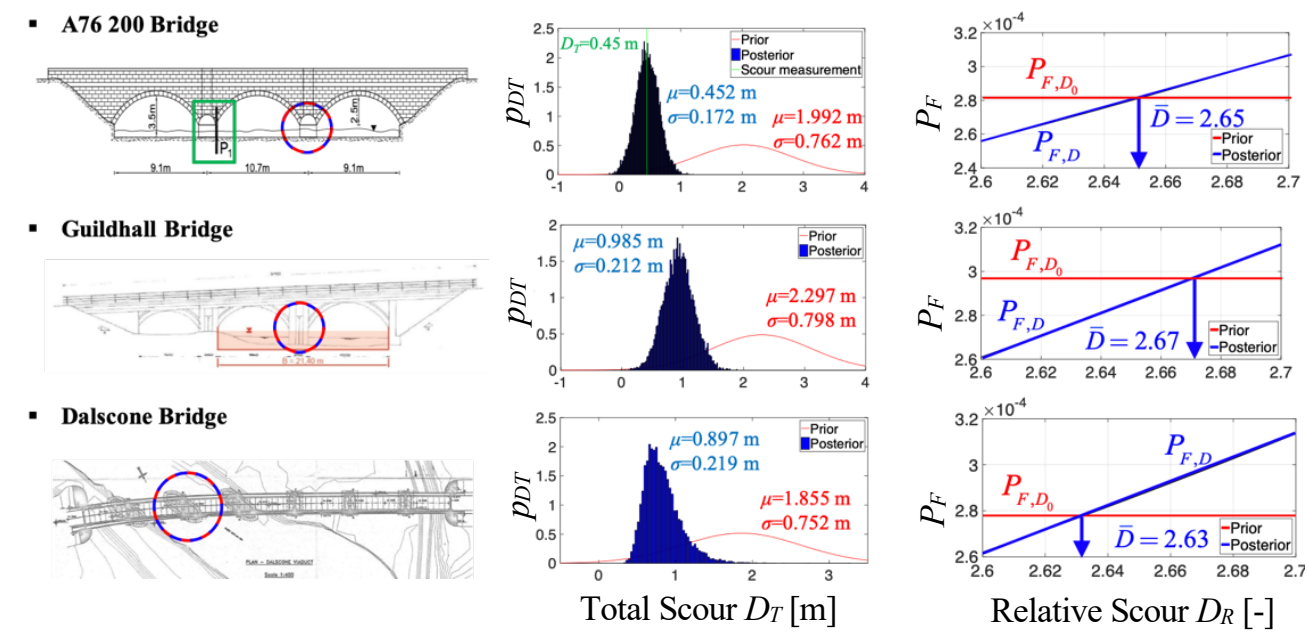

Figure 7. Updating of the scour threshold from BN's outcomes of unmonitored components. 
Starting from a prior threshold $\bar{D}_{0}=2.3$, the posterior estimation of the scour depth updated by the BN allowed increasing the scour threshold to a value of around $\bar{D}=2.66$.

\section{CONCLUSION}

In this paper, a prototype of a DSS for scour risk management for rail and road bridges is presented. It consists of a scour hazard model and a decision model. The former model is based on a $\mathrm{BN}$, which can update the scour depth using river flow characteristics and information from a SMS. The latter model can update the scour threshold after which the bridge is closed by exploiting BN's outcomes and observations collected by a SMS. Case study consisting of three bridges managed by TS in SouthWest Scotland is used to demonstrate the functioning of the DSS.

The probabilistic framework shows that data from scour monitoring systems increase the accuracy on scour estimation of unmonitored, but correlated bridges. This increase is in the order of $70 \%$ (from $76 \mathrm{~cm}$ to $17 \mathrm{~cm}$ ).

BN's outcomes and the observations of the pilot scour monitoring system are used to update the scour threshold that triggers the bridge closure. The outcomes present an increase of the scour threshold that could help transport agencies in reducing the times that bridges might be closed unnecessarily as a precautionary action.

\section{REFERENCE}

1. Wardhana, K. and F. C. Hadipriono. 2003. "Analysis of Recent Bridge Failures in the United States," Journal of performance of constructed facilities, 17(3):144-150.

2. Kirby, A. M., M. Roca, A. Kitchen, M. Escarameia and O. J. Chesterton. 2015. "Manual on scour at bridges and other hydraulic structures," London: CIRIA.

3. van Leeuwen, Z. and R. Lamb. 2014. "Flood and scour related failure incidents at railway assets between 1846 and 2013," Railway Safety \& Standards Board.

4. Briaud, J. L., L. Brandimarte, J. Wang P. and D'Odorico. 2007. "Probability of scour depth exceedance owing to hydrologic uncertainty," Georisk, 1(2):77-88.

5. Tubaldi, E., L. Macorini, B. A. Izzuddin, C. Manes and F. Laio. 2017. "A framework for probabilistic assessment of clear-water scour around bridge piers," Structural safety, 69:11-22.

6. Bolognani, D., A. Verzobio, D. Tonelli, C. Cappello, D. Zonta and B. Glisic. 2017. "An application of Prospect Theory to a SHM-based decision problem," Portland: Proceedings of SPIE.

7. Department for Transport. 2012. "The assessment of scour and other hydraulic actions at highway structures (BD 97/12)," Design manual for roads and bridges.

8. HR Wallingford. 1993. "Hydraulic Aspects of Bridges - Assessment of the Risk of Scour, Report EX2502," HR Wallingford.

9. Transport Scotland. 2018. "Scour Management Strategy and Flood Emergency Plan," Glasgow: Transport Scotland.

10. Network Rail. 2016. "Scotland route: extreme weather plan," Glasgow: Network Rail.

11. Jensen, F. V. and T. D. Nielsen. 2007. Bayesian networks and decision graphs. 2nd Edition. Berlin: Information Science and Statistics, Springer.

12. Ben Gal, I. 2007. "Bayesian Networks," in Encyclopedia of Statistics in Quality \& Reliability, F Ruggeri, F Faltin and R Kennett eds. Chester: Wiley.

13. Faber, M. H., I. B. Kroon, and E. Kragh. 2002. "Risk assessment of decommissioning options using Bayesian networks," Journal of Offshore Mechanics and Artic Engineering, 124:231-238.

14. Bensi, M. T., A. Der Kiureghian and D. Straub. 2011. "A Bayesian network methodology for infrastructure seismic risk assessment and decision support," University of California, Berkeley: Pacific Earthquake Engineering Research Center.

15. Prendergast, L. J. and K. Gavin. 2014. "A review of bridge scour monitoring techniques," Journal of Rock Mechanics and Geotechnical Engineering, 6, 138-149.

16. Ching, J. and J. S. Wang. 2016. "Application of the transitional Markov chain Monte Carlo algorithm to probabilistic site characterization,” Engineering Geology (Engineering Geology), 203:151-167. 